\title{
Reply to the Comment on "The Precipitation of Carbides during Tempering of High Carbon Martensite"
}

(Received March 27, 1972)

Drs. Murphy and Whiteman have raised some questions on our recent paper entitled "The Precipitation of Carbides during Tempering of High Carbon Martensite"(1).

The first point of discussion is concerned with the orientation relationship between $\varepsilon$-carbide and ferrite, and they suggested that the diffraction pattern shown in Photo. 5 in reference ( 1 ) indicated the Doi-Nishiyama orientation relationship rather than that by Jack. A close examination of the patterns shown in Photos. 5 and 9 in reference (1), however, demonstrated that the orientation relationship is much closer to that of Jack as shown in Table 1 . It should be noted that
Murphy and Whiteman that the $(100)_{x}$ reflection is the most positive evidence of the $\chi$-carbide, though we could not obtain it unfortunately. In fact, a majority of the patterns are difficult to separate whether they are $\chi$ carbide or cementite as shown in Photo. 1 (a). Namely this pattern appears to be explained as either cementite (Photo. 1 (b)) or $\chi$-carbide (Photo. 1 (c)). It is interesting to note that, even in this orientation, the $d$-spacings agree with those of $\chi$-carbide within the error of $0.5 \%$, but are deviated more than $3 \%$ from those of cementite. (Similar results were also obtained by Murphy et al. as shown in Fig. 3 in reference (4)). In some cases, however, it is more easy to distinguish the difference as

Table 1 The angles separating the $\varepsilon$-carbide reflections from those of the ferrite.

\begin{tabular}{|c|c|c|c|c|c|c|}
\hline \multirow{2}{*}{$\begin{array}{l}\text { Photo. } \\
\text { number }\end{array}$} & \multirow{2}{*}{ Crystal planes } & \multirow{2}{*}{$\begin{array}{l}\text { Observed } \\
\text { angles } \\
\text { between } \\
\text { the spots }\end{array}$} & \multicolumn{2}{|c|}{$\begin{array}{l}\text { Apparent angles expected in } \\
\text { the patterns for }\end{array}$} & \multicolumn{2}{|c|}{$\begin{array}{l}\text { True angles separating } \\
\text { the planes for }\end{array}$} \\
\hline & & & $\begin{array}{l}\text { Doi-Nishiyama } \\
\text { relationship }\end{array}$ & $\begin{array}{l}\text { Jack } \\
\text { relationship }\end{array}$ & $\begin{array}{l}\text { Doi-Nishiyama } \\
\text { relationship }\end{array}$ & $\begin{array}{l}\text { Jack } \\
\text { relationship }\end{array}$ \\
\hline $\begin{array}{l}\text { Photo. } 5 \\
\text { in ref. (1) }\end{array}$ & $\begin{array}{l}(\overline{2} 2 \overline{2})_{m} \&(\overline{11} 20) \varepsilon_{2} \\
(110)_{m} \&(\overline{110}) \varepsilon_{2} \\
(110)_{m} \&(10 \overline{1} 0) \varepsilon_{1} \\
(\overline{1} 3 \overline{2})_{m} \&(01 \overline{1} 2) \varepsilon_{1}\end{array}$ & $\begin{array}{l}8^{\circ} \\
7^{\circ} \\
2^{\circ} \\
1^{\circ}\end{array}$ & $\begin{array}{l}4.5^{\circ} \\
4^{\circ} \\
0^{\circ} \\
2.5^{\circ}\end{array}$ & $\begin{array}{l}8.5^{\circ} \\
8^{\circ} \\
2.5^{\circ} \\
1^{\circ}\end{array}$ & $\begin{array}{l}5^{\circ} \\
4.5^{\circ} \\
0^{\circ} \\
3.5^{\circ}\end{array}$ & $\begin{array}{c}10^{\circ} \\
9^{\circ} \\
5^{\circ} \\
1.5^{\circ}\end{array}$ \\
\hline $\begin{array}{l}\text { Photo. } 8 \\
\text { in ref. (1) }\end{array}$ & $\begin{array}{l}(110)_{m} \&(10 \overline{1} 0) \varepsilon \\
4 \overline{1} 3)_{m} \&(1 \overline{1} 02) \varepsilon\end{array}$ & $\begin{array}{l}2^{\circ} \\
3^{\circ}\end{array}$ & $\begin{array}{l}0^{\circ} \\
5.5^{\circ}\end{array}$ & $\begin{array}{l}2.5^{\circ} \\
2^{\circ}\end{array}$ & $\begin{array}{l}0^{\circ} \\
5.5^{\circ}\end{array}$ & $\begin{array}{l}5^{\circ} \\
4^{\circ}\end{array}$ \\
\hline
\end{tabular}

the apparent angles in the patterns are different from the true values. Such a situation arises out of the fact that the reflections can often be obtained also in the case where the Bragg conditions are insufficiently satisfied. For the growth direction of the $\varepsilon$-carbide needles, our results are not sufficient to determine it unambiguously. This is because both the diffraction patterns involving the ferrite and $\varepsilon$-carbide reflections simultaneously and the associated dark field images using the $\varepsilon$-carbide reflections are needed to achieve a significant trace analysis. Furthermore, as shown by Tekin et al. ${ }^{(2)}$ and Murphy et al. ${ }^{(3)}$, the $\varepsilon$-carbide was wavy in shape, and it was difficult to determine a specific growth direction. In our restricted experiment, however, the overall growth direction was compatible with the $\langle 211\rangle_{\alpha} / /(01 \overline{1} 0)_{\varepsilon}$ which was determined Murphy et al. ${ }^{(3)}$

The second question of the comment is about the



(1) Y. Ohmori and S. Sugisawa : Trans. JIM, 12 (1971), 170.

(2) E. Tekin and P.M. Kelly : Precipitation from Iron Base Alloys, AIME, New York, (1965), p. 173.

(3) S. Murphy and J. A. Whiteman : Met. Trans., 1 (1970), 843.

(4) S. Murphy, J.A. Whiteman, and J.H. Woodhead : The Mech. of Phase Tr. in Cryst. Sol., ISI Mon. 33, London, (1969), p. 72. shown in Photo. 9 in reference (1). Dr. Murphy et al. suggested that this pattern could be interpreted in terms of the cementite reflections belonging to two reflecting zones. To answer this proposal, nothing more than the enlargement of the pattern shown in Photo. $9^{(1)}$ will be necessary. Photograph 2 is the low angle region of Photo. 9 of reference (1), and it can be seen that the alternative identification proposed by Dr. Murphy et al. is impossible to achieve. Thus one must conclude that their interpretation is incorrect. Some other patterns showing the existence of $\chi$-carbide will be available in our recent paper $^{(5)}$ as well. Another evidence of $\chi$-carbide is the result of the magnetic measurement by our colleague, Watanabe ${ }^{(6)}$, who measured the saturation magnetization during heating and cooling of the same $1.22 \% \mathrm{C}$ martensite at a rate of $5^{\circ} \mathrm{C} / \mathrm{min}$ up to either 400 or $600^{\circ} \mathrm{C}$. The Curie point of the carbide in the martensite tempered up to $400^{\circ} \mathrm{C}$ where a majority of the $\chi_{\text {-carbide }}$ precipitates still exist ${ }^{(5)}$ was $238^{\circ} \mathrm{C}$, whereas tempering up to $600^{\circ} \mathrm{C}$ reduced it to $200^{\circ} \mathrm{C}$, a typical cementite Curie point, as can be seen in Fig. 1. (Similar results have already been confirmed by Crangle and Sucksmith(7),

(5) Y. Ohmori : Trans. JIM, 13 (1972), 119.

(6) S. Watanabe : unpublished work.

(7) J. Crangle and W. Sucksmith : J. Iron Steel Inst., 168 (1951), 141. 
(b)



$3 \overline{2} \mathrm{O}$

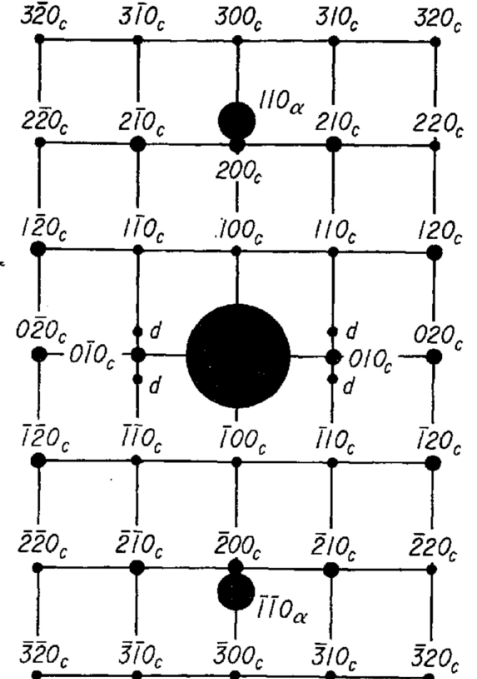

(c)

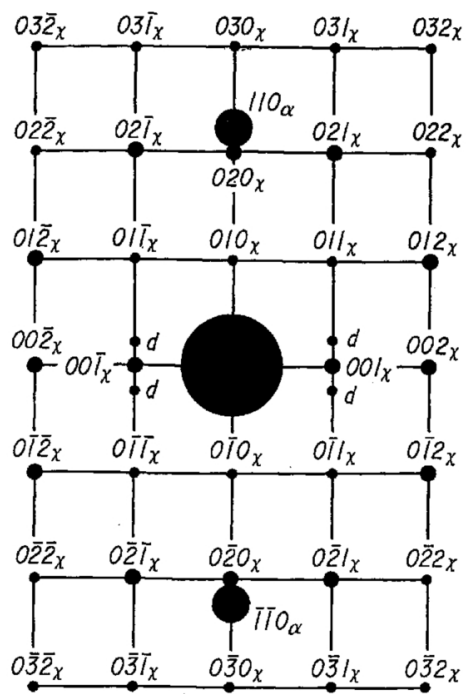

Photo. 1 The selected area electron diffraction pattern from the twin-nucleated carbide in the $1.22 \% \mathrm{C}$ martensite tempered up to $330^{\circ} \mathrm{C}$ at a heating rate of $5^{\circ} \mathrm{C} / \mathrm{min}$.

(a) The diffraction pattern, (b) the identification as cementite, and (c) the identification as $\chi$ carbide. (The $d$-spacings are much closer to $\chi$-carbide.)


Photo. 2 The low angle region of Photo. 9 in reference (1).

(a) the diffraction pattern, and (b) its schematic representation.

Okada and Arata ${ }^{(8)}$, and Murphy et al. ${ }^{(4)}$, but Watanabe's results are important in that he confirmed it in the same steel with the exactly same tempering process.). Further evidences of $\chi$-carbide are due to the results of $\mathrm{X}$-ray diffraction by Okada and Arata ${ }^{(8)}$ and by Fau et al. ${ }^{(9)}$ Fau et al. ${ }^{(\theta)}$ have shown that the results of X-ray diffraction of the carbide extracted from the $0.96 \% \mathrm{C}$ martensite tempered at $305^{\circ} \mathrm{C}$ for $15 \mathrm{hr}$ can be interpreted in terms of the monoclinic $\chi$-carbide but not by cementite.

The final problem is the evidence of the cementite formation at the temperatures as low as $135^{\circ} \mathrm{C}$ in a high nickel steel. The first point we have to point out is the fact that the precipitation is not determined only by tempering temperature, but also is the function of tempering time. The tempering in our experiment was

(8) M. Okada and Y. Arata: J. Japan Inst. Metals, 19 (1955), 186.

(9) P. Fau, R. Bigot, and R. Faivre : C. R. Acad. Sc. Paris, 264 (1967), Série C, 171.



Fig. 1 The results of magnetic measurement during the tempering of the $1.22 \% \mathrm{C}$ martensite (by S. Watanabe).

carried out with a heating rate of $5^{\circ} \mathrm{C} / \mathrm{min}$, but was not achieved isothermally. Thus it is not possible to compare our results with those obtained by the isothermal treatment. Second, the chemical compositions are completely different, and the large amount of nickel may alter the rate and the temperature range of the 
carbide precipitation. Finally, in the analysis shown in Fig. 3 (b) in the comment by Dr. Murphy et al., it seems questionable that the reflections arising from the $(100)_{c}$ and $(001)_{c}$ were not observed, because both reflections are normally strongly excited. If the reflections such as $(101)_{c}$ and $(202)_{c}$ come from the carbide precipitated, it will be also possible to index these reflections in a different way; i.e., the reflections given as the $(002)_{c}$ or the $(204)_{c}$ can be explained in terms of the double reflections due to the $(110)_{\alpha^{\prime}}$. The other spots can be identified in a similar fashion. Therefore, further information will be necessary to claim it as cementite. As for the twin-nucleated cementite/ferrite orientation relationship, the Isaichev relationship is a plausible one, since the $(101)_{c} \sim / /(112)_{\alpha}$ is the minimum misfit plane
(This (112) $)_{\alpha}$ plane is the twin plane). In the steel used in our experiment, however, the observed result was much closer to the Bagaryatskii orientation relationship as demonstrated in our recent paper ${ }^{(5)}$. And if the analysis in Fig. $3(\mathrm{~b})$ in the comment were correct, the pattern would not give the Isaichev orientation relationship. Namely the angles separating the $(200)_{c}$ and the $(01 \bar{I})_{\alpha^{\prime}}$, and the $(002)_{c}$ and the $(211)_{\alpha^{\prime}}$ are both $1^{\circ}$, indicating that the orientation relationship is $1^{\circ}$ from that of Bagaryatskii but about $2.5^{\circ}$ from that of Isaichev.

By Y. Ohmori and S. Sugisawa

Central Research Laboratories, Sumitomo Metal Industries, Ltd., Amagasaki, Japan. 